\title{
High sedimentary oxygen consumption indicates that sewage input from small islands drives benthic community shifts on overfished reefs
}

\author{
AMANDA K. FORD ${ }^{* 1,2}$, NANNE VAN HOYTEMA ${ }^{1,2}$, \\ BRADLEY R. MOORE ${ }^{3}$, LINA PANDIHAU ${ }^{4}$, CHRISTIAN WILD ${ }^{2}$ AND \\ SEBASTIAN C. A. FERSE ${ }^{1}$ \\ ${ }^{1}$ Leibniz Center for Tropical Marine Research (ZMT), Fahrenheitstrasse 6, 28359 Bremen, Germany, ${ }^{2}$ Faculty of \\ Biology and Chemistry (FB2), University of Bremen, Bremen, Germany, ${ }^{3}$ Coastal Fisheries Programme, Pacific \\ Community (SPC), Noumea, Nem Caledonia and ${ }^{4}$ National Fisheries Authority (NFA), Port Moresby, Papua \\ Nem Guinea \\ Date submitted: 31 May 2016; Date accepted: 13 January 2017; First published online 28 \\ February 2017
}

THEMATIC SECTION

Humans and Island Environments

\section{SUMMARY}

Small-island coral reef ecosystems are usually closely coupled to the activities of human inhabitants. Ahus Island (Papua New Guinea) is an isolated Pacific island with a rapidly growing population, heavy reliance on marine resources and limited infrastructure. We hypothesized that untreated sewage was driving distinct benthic assemblages around Ahus and neighbouring uninhabited Onetah. At sites with varying proximities to beach toilets, fore-reef herbivorous fish biomass and benthic composition were measured alongside reef-flat sedimentary oxygen consumption (SOC); a high SOC rate reflects high organic input into coastal waters, thus serving as a potential indicator of sewage input. Fish biomass was low (17.1-20.1 $\mathrm{g} \mathrm{m}^{-2}$ ), but consistent between sites. However, cyanobacteria dominated the fore-reef closest to toilets $(62 \pm 3 \%)$ with highest reef-flat SOC, whereas hard corals dominated furthest away $(63 \pm$ $1 \%$ ), where SOC was lowest. To our knowledge, this is the first study that used SOC to detect local differences in sewage pollution. The results indicate that whilst corals can maintain their dominance on overfished reefs, additional sewage stress may drive pronounced benthic shifts, highlighting the urgency to improve small-island waste management.

Keymords: phase shifts, sewage, sedimentary oxygen consumption, herbivorous fish, cyanobacteria, waste management, small-island communities, coral reefs, overfishing

\section{INTRODUCTION}

Island communities, such as those in the Pacific, have a particularly strong reliance on coral reef ecosystem services

\footnotetext{
*Correspondence: Amanda K. Ford e-mail: amanda.ford@ leibniz-zmt.de

Supplementary material can be found online at https://doi.org/10.1017/S0376892917000054
}

such as food, livelihoods and coastal protection. Often the high dependence on these services is coupled with a very low capacity to adapt to their loss (Burke et al. 2011), rendering these communities highly vulnerable to reef degradation. Modern influences and coastal population growth on Pacific islands have led to surges of non-traditional fishing methods (Hamilton et al. 2012), declining water quality and land-use change (Zann 1994), which are threatening coral reef integrity. An amalgamation of climate change and local stressors often results in the replacement of hard corals with alternative benthic organisms, which frequently leads to a decline of structural complexity with associated reductions of ecosystem services (Pratchett et al. 2014). Small-island ecosystems are uniquely fragile to disturbance due to their close coupling with the effects of human inhabitants.

Knowing where to focus management depends on determining and extracting information on relevant key drivers of degradation at different localities. Whilst relatively simple methods for measuring herbivorous fish communities are well established, assessing nutrient and organic matter $(\mathrm{OM})$ input remains challenging in areas with limited infrastructure due to difficulties regarding sample storage, processing and measurements. Studies have proposed suitable indicators of changes in water quality (Cooper et al. 2009; Fabricius et al. 2012), but measurements are often static (e.g. macroalgal abundance, coral tissue thickness), and generally require laboratory facilities at some point (e.g. stable isotope analyses, exogenous sediment analyses - see Risk et al. 2001). Furthermore, despite sewage-based OM input having been recognized as a key problem for reefs worldwide for many decades (e.g. Barnes 1973), there remains a distinct lack of in situ studies that investigate its impacts (Wear \& Thurber 2015). Rapidly growing populations and limited infrastructure make sewage treatment a critical issue on small islands.

To interpret ecosystem responses and trajectories that can provide important quantitative metrics for setting specific conservation goals, simple in situ indicators are required. The current study extended existing in situ methods for determining local pollution by exploring the potential for sedimentary oxygen consumption (SOC) incubations to assess 


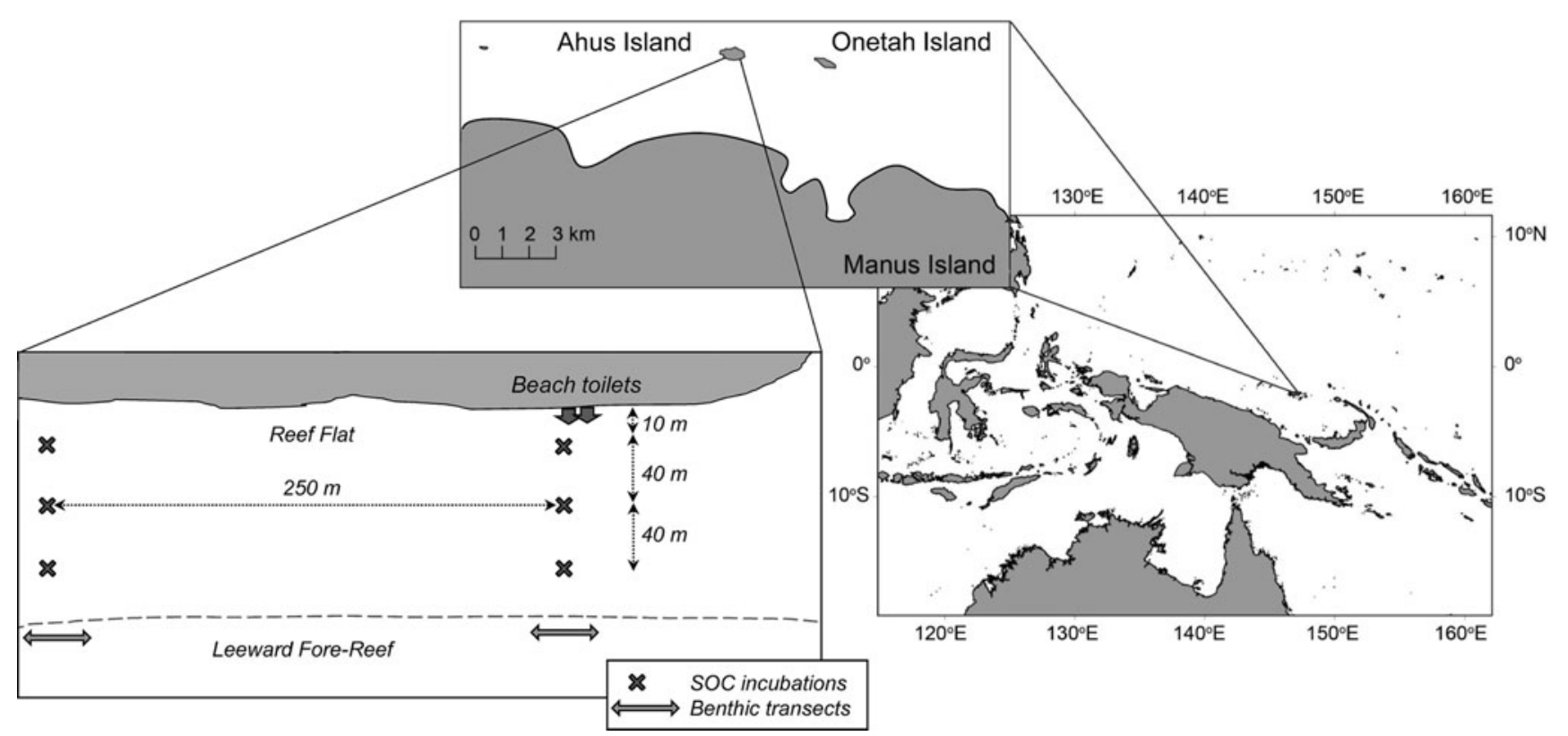

Figure 1 Map of study sites on the north coast of Manus Island, Papua New Guinea, including schematic diagram (bottom-left box) showing locations for SOC incubations and fore-reef benthic transects for the sites Ahus BT (right) and Ahus non BT (left). SOC = sedimentary oxygen consumption.

local anthropogenic OM input promptly in the field. In shallow-water reef environments with primary benthic cover by permeable sediments, intense benthic-pelagic coupling causes sediments to integrate $\mathrm{OM}$ concentration changes in the overlying water (Wild et al. 2005). As key organic components of sewage are rapidly recycled in surface sediments (Wild et al. 2008), elevated SOC rates should directly reflect recent sewage $(\mathrm{OM})$ input. Sedimentary $\mathrm{OM}$ is less subject to short-term fluctuations than water column $\mathrm{OM}$, implying that SOC indicates long-term processes more reliably than assessments of water parameters. If found to distinguish differences in local OM input, then SOC measurements have strong applicability to future studies in remote environments with limited infrastructure due to their simplicity and immediate results, thus offering a potential tool for island monitoring and research.

By measuring SOC alongside benthic and fish community assessments, this study aimed to investigate the roles of both overfishing and anthropogenic $\mathrm{OM}$ input in driving distinct benthic community assemblages of reefs fringing two small neighbouring barrier islands - Ahus and Onetah - in Papua New Guinea (PNG; Fig. 1). Ahus Island is densely populated $(c .700$ people, which equates to $c .2500$ people $\mathrm{km}^{-2}$ ) with a heavy dependency on marine resources; $77 \%$ of households rate fishing as their primary income (Cinner 2005), compared to the regional coastal community average of 29.5\% (Pinca et al. 2010). This dependency has resulted in high pressure on local reef fish populations, to such an extent that Ahus' fish biomass is now among the most degraded worldwide (MacNeil et al. 2015). Additionally, Ahus lacks sewage treatment facilities, with raw sewage directly reaching the reef-flat at specific points (originating from around ten beach toilets on the island's shoreline, located over the water at $c a .5 \mathrm{~m}$ from the shore), thus providing an ideal opportunity to investigate the in situ impacts of anthropogenic OM input. Ahus' human population has increased rapidly over recent decades: the local district's population grew by $36 \%$ between 2000 and 2011 (National Statistical Office 2014), and consequently relative sewage input and fishing pressure will have increased significantly. By contrast, Onetah ( $3 \mathrm{~km}$ east) is uninhabited, although its reefs also fall under Ahus' customary marine tenure as a fishing ground.

These study sites provided a unique opportunity to explore two islands within the same tenure system that exhibit different anthropogenic influences regarding sewage pollution. We hypothesized that (i) benthic assemblages are significantly different between Ahus and Onetah, but (ii) because of the customary marine tenure and accessibility, herbivorous fish communities are comparable. We thus further hypothesized that (iii) benthic community differences are significantly linked to proximity to beach toilets, and (iv) SOC rates will reflect higher OM degradation closer to beach toilets.

\section{MATERIALS AND METHODS}

The two islands that were studied are located just north of Manus Island, northern PNG (Fig. 1). Two sites were selected on the leeward side of Ahus $\left(147^{\circ} 6^{\prime} \mathrm{E}, 1^{\circ} 56^{\prime} \mathrm{S}\right)$ directly adjacent to beach toilets ('Ahus BT'), and along the shore 
at $250 \mathrm{~m}$ from beach toilet influence ('Ahus non BT'). A third site was selected on the leeward side of uninhabited Onetah ('Onetah Control': $147^{\circ} 8^{\prime} \mathrm{E}, 1^{\circ} 57^{\prime} \mathrm{S}$ ). Sites were consistent regarding exposure, orientation, bathymetry and distance from mainland. All fieldwork was carried out during May and June 2014.

To determine benthic community composition at the leeward fore-reef, $25-\mathrm{m}$ transects $\left(n=3\right.$ site $\left.^{-1}\right)$ were deployed at 3-m depths parallel to, and at $120-150 \mathrm{~m}$ distance from the shore. Cover type was recorded every $25 \mathrm{~cm}(\mathrm{n}=$ 100 transect $^{-1}$ ) using the point-intercept method. Where cyanobacterial mats were observed, they were distinguished between growing over dead substrate or sand ('cyanobacteria') and growing over live Halimeda spp. ('cyanobacteria on macroalgae'). Juvenile corals $(<3 \mathrm{~cm})$ were counted within $0.25-\mathrm{m}^{2}$ quadrats $\left(\mathrm{n}=10\right.$ transect $\left.^{-1}\right)$ using a GOBE Nightsea UV lamp for fluorescence detection (Piniak et al. 2005). Herbivorous fish biomass was quantified using the distance sampling underwater visual census method (Labrosse et al. 2002); two divers recorded abundances and fork lengths of all observed fish along 50-m transects $\left(n=6\right.$ site $\left.^{-1}\right)$ at each island's leeward fore-reef. Length and spacing of transects as well as movement patterns and extensive home ranges of some species precluded comparisons between the two Ahus sites. Data were converted to biomass using established speciesspecific length-weight relationships (Froese \& Pauly 2013). Herbivorous fishes were classified into four key functional groups that exhibit distinct roles of algal removal: browsers, grazers and detritivores, scrapers and small excavators, and large excavators and bioeroders (Green \& Bellwood 2009).

Due to the proximity to OM input and the homogeneous shallow environment, and in order to document any potential changes from the shore towards the fore-reef, SOC measurements were carried out on the reef-flat at 10,50 and $90 \mathrm{~m}$ from the shore $\left(\mathrm{n}=8-10\right.$ distance $^{-1}$ site $\left.^{-1}\right)$. Cut 50 $\mathrm{mL}$ syringes were used to collect $10-\mathrm{mL}$ surface sediment cores $(1 \mathrm{~cm}$ depth), which were placed into $160-\mathrm{mL}$ glass vials and filled with water from the overlying water column. $\mathrm{O}_{2}$ concentration was recorded prior to vials being sealed airtight, ensuring no air bubbles remained, and these were incubated in situ inside opaque bags for $c a$. 2 hours (Onset $\mathrm{HOBO}^{\circledR}$ pendant temperature and light loggers confirmed that light was excluded), following which $\mathrm{O}_{2}$ was re-measured. $\mathrm{O}_{2}$ concentrations were measured using an $\mathrm{O}_{2}$ optode sensor with a conductivity probe (MultiLine ${ }^{\circledR}$ IDS 3430, WTW GmbH, Weilheim, Germany; accuracy: $\pm 0.5 \%$ of measured value) $1 \mathrm{~cm}$ above the sediment after the water was stirred. Temperature and salinity were monitored throughout in order to confirm consistency. $\mathrm{O}_{2}$ consumption in control chambers containing only water from the overlying water column ( $\mathrm{n}=5-6$ distance $^{-1}$ site $\left.^{-1}\right)$ was averaged and subtracted from SOC rates. After accounting for incubation time, vial volume and control measurements, SOC values were calculated to hourly rates per volume of surface sediment: $\mu \mathrm{g} \mathrm{O}_{2} \mathrm{~cm}^{-3}$ sediment $\mathrm{h}^{-1}$.
To evaluate statistical differences between sites, benthic community transect data were entered into a principal components analysis (PCA) using the $\mathrm{R}$ prcomp ( $\mathrm{R}$ base package version 3.1.1; R Development Core Team 2013) and ggbiplot (ggplot2 package; Wickham 2009) functions. Fish biomass data were tested by PERMANOVA using the Bray-Curtis similarity coefficient in PRIMER v.6 and PERMANOVA+ (PRIMER-E, Plymouth, UK), with 'island' as the fixed factor, using type 3 sums of squares and unrestricted permutation of raw data. Juvenile coral data were compared between sites by negative binomial regression using the $\mathrm{R} M A S S$ package (Venables \& Ripley 2002), which amended previous overdispersion. SOC data were tested for independent and combined effects of 'site' and 'distance from shore' using two-way ANOVA hypothesis testing through the $\mathrm{R}$ aov function ( $\mathrm{R}$ base package version 3.1.1). Lastly, dominant benthic groups of hard corals and cyanobacteria (including cyanobacteria on macroalgae) were compared between sites using one-way ANOVA. ShapiroWilk normality tests confirmed normality $(p>0.05)$ of SOC rates, hard coral and $\log (+1)$-transformed cyanobacteria data. Post hoc Tukey honest significant difference tests explored significant differences between groups.

\section{RESULTS}

Benthic assemblages differed significantly between the leeward fore-reefs of all sites (Fig. 2(a)). A PCA of the benthic communities emphasized these differences by distinguishing three distinct clusters according to site (Fig. 2(b)), with the first two components explaining $62.6 \%$ of the variation. The dominant benthic organisms - hard coral and cyanobacteria were strongly associated to site (one-way ANOVA: hard coral $-F_{(2,6)}=50.03, p<0.001$; cyanobacteria $-F_{(2,6)}=59.37$, $p<0.001)$, with hard coral decreasing and cyanobacteria increasing as sites increased in proximity to beach toilets. Directly in front of the beach toilets (Ahus BT), cyanobacteria dominated $(62 \pm 3 \%$; mean $\pm \mathrm{SE})$, growing either on solid substrates $(17 \pm 2 \%)$ or on macroalgae ( $44 \pm 2 \%)$. Hard coral cover $(12 \pm 0.1 \%)$ and juvenile coral abundances $(1.3 \pm 0.5$ juveniles $\mathrm{m}^{-2}$ ) were both low. Further from direct OM input (Ahus non BT), the reef was characterized by significantly lower cyanobacteria $(14 \pm 6 \%)$ and higher hard coral cover $(30 \pm 4 \%)$, though juvenile corals were still rare $(1.3 \pm 0.4$ juveniles $\mathrm{m}^{-2}$ ). At the furthest point from OM input (Onetah Control), coral cover was high $(63 \pm 1 \%)$ and cyanobacteria were negligible $(<2 \%)$, and juvenile corals $(4.0 \pm 0.5$ juveniles $\mathrm{m}^{-2}$ ) were significantly more abundant than at the other sites $(z=2.3, p=0.02)$.

Distinct differences in benthic communities were not reflected in herbivorous fish populations; biomass was neither significantly different within functional groups nor in total between islands (PERMANOVA; $F_{(1,10)}=0.32, p>0.05$; Fig. 3). However, SOC rates were greater at sites closer to beach toilets (two-way ANOVA; $F_{(2,77)}=24.83, p<0.001$; Fig. 4), indicating higher OM degradation. Distance from 

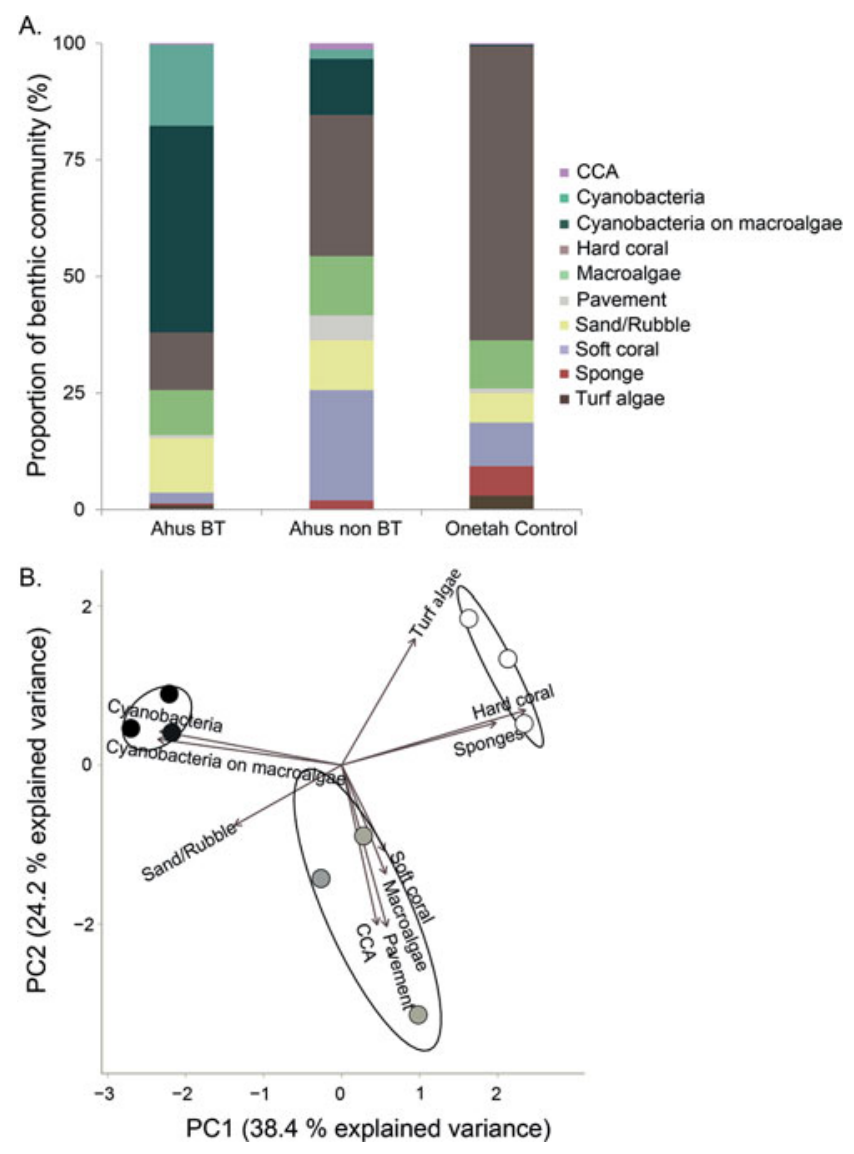

Figure 2 (a) Benthic community composition across the three sites. (b) Principal components analysis clusters the sites (Ahus BT $=$ black circles; Ahus non BT $=$ grey circles; Onetah Control $=$ white circles) into distinct groups according to benthic composition of each transect $\left(\mathrm{n}=3\right.$ site $\left.^{-1}\right)$. The first (PC1) and second (PC2) principal components combined explain $62.6 \%$ of the variance. $\mathrm{CCA}=$ crustose coralline algae.

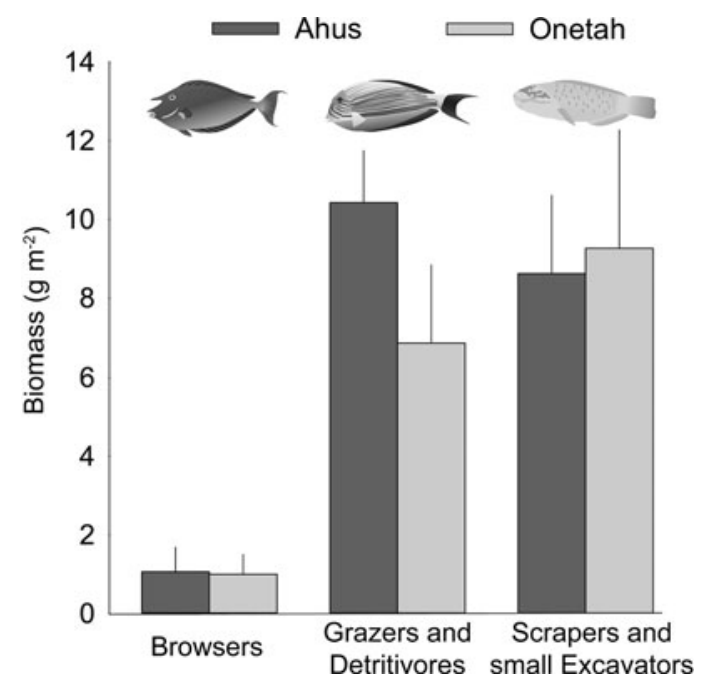

Figure 3 Biomass values of herbivorous fish functional groups browsers, grazers and detritivores, and scrapers and small excavators - for each island. Largge excavators and bioeroders were not observed, and thus are not included in the graph.

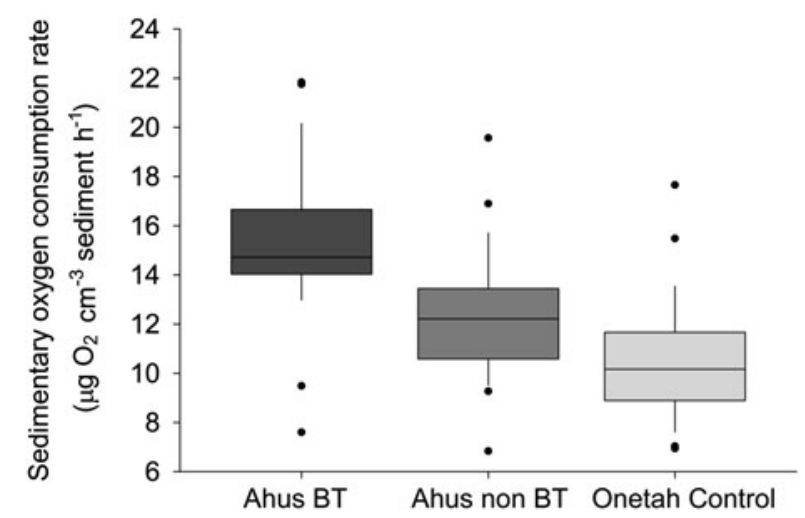

Figure 4 Sedimentary oxygen consumption rates for each site.

shore did not affect SOC rates $\left(F_{(2,74)}=0.04, p=0.96\right)$, and this did not vary among sites $\left(F_{(4,74)}=2.30, p=0.066\right.$; Supplementary Figure S1, available online), indicating the potential of land-derived OM to affect adjacent reefs even when separated by a reef-flat of at least $90 \mathrm{~m}$.

\section{DISCUSSION}

The results underline the strong potential effects of smallisland sewage-based OM input on the reef environment. Coral reef assemblages differed significantly between sites, with reefs closest to and furthest from the beach toilets being dominated by cyanobacterial mats and hard corals, respectively. While herbivorous fish biomass was not different between the islands, SOC rates were greater at sites closer to beach toilets. As both islands show equal herbivorous fish biomass, it is not possible to ascertain the specific contribution of herbivory relative to $\mathrm{OM}$ input on reef condition. However, the results suggest that anthropogenic OM input from sewage has a significant role in structuring benthic communities when herbivory remains consistent and low between sites.

\section{Overfishing of herbivorous fish}

The dependency of Ahus fishers on reef fish, coupled with the rapidly growing human population, promotes increasing use of non-traditional methods (e.g. night-time spearfishing) to maximize catches, thus intensifying pressure on already depleted resources. Total herbivorous fish biomass was consistently low (Onetah $17.1 \pm 3.0 \mathrm{~g} \mathrm{~m}^{-2}$, Ahus $20.1 \pm$ $3.4 \mathrm{~g} \mathrm{~m}^{-2}$ ), implying that Onetah's reefs are fished to the same extent as Ahus'. Herbivore biomass values are actually below notably overexploited Pacific islands such as the Main Hawaiian Islands $\left(>30 \mathrm{~g} \mathrm{~m}^{-2}\right.$; Friedlander \& DeMartini 2002). Ahus' fish stocks are projected to require 59 years to recover if fishing were stopped (MacNeil et al. 2015), and our results imply that recovery times will be similar at Onetah. Herbivorous fish communities play a central role in reef function and dynamics, and are important in maintaining reef resilience (Hughes et al. 2007). Therefore, it is likely that 
these fished reefs are less able to resist and recover from other stressors (e.g. declining water quality), adding complexity to the interpretation of our findings.

\section{Factors driving local benthic communities}

The islands depict a common picture of overexploited fish communities and low water quality. We suggest that the results allow for the following two interpretations: (i) even when herbivorous fish populations are heavily exploited, healthy hard coral-dominated systems can be maintained when water quality is high, but (ii) under such reduced levels of herbivorous fish, OM input can have severe consequences for reef health.

Significant differences in both cyanobacteria abundance and reef-flat SOC rates among sites (highest closest to beach toilets) indicate that $\mathrm{OM}$ input is driving cyanobacterial mat proliferation. In the Caribbean, a region that is also characterized by chronically low levels of herbivores (Roff \& Mumby 2012), OM degradation facilitates the release of sedimentary iron and phosphate, promoting mat development (Brocke et al. 2015a). Similarly, organic carbon, phosphorous and iron input stimulated mat growth in Australia (Albert et al. 2005). Once established, cyanobacterial mats release up to $79 \%$ of the total reef community's dissolved organic carbon (DOC) (Brocke et al. 2015b), thus promoting further bacterial proliferation, which can indirectly result in declining reef health through mechanisms such as increasing coral disease prevalence (Kline et al. 2006). Furthermore, cyanobacteria reduce coral recruitment (Kuffner \& Paul 2004), supporting the observed juvenile coral densities, and they exhibit some of the highest reef nitrogen fixation rates (Cardini et al. 2014), which may further favour reef degradation.

\section{SOC incubations as a simple and cost-effective monitoring tool}

Elevated SOC rates indicate higher OM degradation at sites closer to beach toilets, demonstrating the ability of this method to identify sedimentary signals of localized sewage input on coral reef sediments. Interestingly, the lack of differences in SOC rates among different distances from the shore implies that OM homogeneously affects sediments up to at least $90 \mathrm{~m}$ from the source, perhaps due to tidal mixing across the reef-flat (being almost dry at lowest tide). Nonetheless, the capacity to distinguish significant differences at larger distance intervals $(\geq 250 \mathrm{~m})$ from sewage input demonstrates the potential for rapidly comparing local pollution in situ in remote (island) situations where infrastructure and equipment are limiting. While this measurement in itself provides a useful proxy for comparing OM input at a local scale within a coastal zone, combining it with other measurements could allow for further interpretations. For example, subsequent analyses of sedimentary lipids such as coprostanol (O'Leary et al. 1999), stable isotopes of nitrogen, bacterial communities and/or exogenous (anthropogenically derived) sediment contribution would enable identification of the pollution source (Risk et al. 2001, 2009).

\section{Ecological perspective and management implications}

OM-driven proliferation of benthic cyanobacterial mats may stimulate a positively reinforcing cycle whereby limiting nutrients become readily available (phosphate from sedimentary OM degradation, DOC and bioavailable nitrogen release from mats) and further promote reef degradation. As few organisms feed on cyanobacteria due to poor nutritional quality and chemical defences (Nagle \& Paul 1998), and mats inhibit key processes (e.g. coral recruitment; Kuffner \& Paul 2004), this cycle may become increasingly challenging to reverse. Considering that most reefs are overfished and projected recovery times are extensive (35 years on average; MacNeil et al. 2015), it is critical to manage water quality in order to provide reefs with the best chance to maintain coral cover and to facilitate recruitment, especially in smallisland environments, which are particularly sensitive to anthropogenic impacts.

Management of fisheries and water quality should be accompanied by support of alternative livelihoods and food sources for island communities in a holistic management approach. A limitation of small coral islands is the scarcity of arable land (Catala 1957) and infrastructure. One potential management tool that considers these needs and limitations is the installation of composting toilets, after due consideration of local culture. This could improve future food security of vulnerable communities by (i) improving production of land-based resources and (ii) promoting the recovery of fish stocks by both decreasing reliance on marine resources and reducing nutrient and OM levels that are detrimental to reef health. Such holistic management approaches are likely to meet with more success than strict limitations on fishing efforts that do not address the needs of island communities in terms of food security and livelihoods.

\section{ACKNOWLEDGEMENTS}

Firstly, we would like to thank the editors and the three anonymous reviewers for their contributions to this manuscript. This work was undertaken during a joint research campaign by the National Fisheries Authority (NFA) of Papua New Guinea and the Secretariat of the Pacific Community (SPC). We would like to acknowledge the staff at the NFA for their support and assistance throughout our project, particularly Ludwig Kumoru, Leban Gisawa and Lorel Dandava. Furthermore, we would like to thank the members of the SPC-NFA-Manus Provincial Fisheries climate change monitoring team (Aaranteiti Kiareti, Robinson Liu, Philip Sokou, Marina Meombi, Venna Pokana, Bredlee Murray and Kanawi Pomat), who provided us with support and infrastructure on site and assisted with the collection of finfish data. Finally, we thank the communities on Ahus for their 
warm hospitality and permission to carry out research on their land.

\section{FINANCIAL SUPPORT}

This work was supported by the (German) Federal Ministry of Education and Research (BMBF) through the 'Nachwuchsgruppen Globaler Wandel $4+1$ ' (REPICORE, grant number 01LN1303A), the European Union through the 'Scientific Support for the Management of Coastal and Oceanic Fisheries in the Pacific Islands Region' ('SciCOFish') initiative, the Australian Government's Department of Foreign Affairs and Trade (DFAT) and the National Fisheries Authority of Papua New Guinea.

\section{Supplementary material}

To view supplementary material for this article, please visit https://doi.org/10.1017/S0376892917000054

\section{References}

Albert, S., O’Neil, J.M., Udy, J.W., Ahern, K.S., O’Sullivan, C.M. \& Dennison, W.C. (2005) Blooms of the cyanobacterium Lyngbya majuscula in coastal Queensland, Australia: disparate sites, common factors. Marine Pollution Bulletin 51: 428-437.

Barnes, E.S. (1973) Sewage pollution from tourist hotels in Jamaica. Marine Pollution Bulletin 4: 102-105.

Brocke, H.J., Polerecky, L., de Beer, D., Weber, M., Claudet, J. \& Nugues, M.M. (2015a) Organic matter degradation drives benthic cyanobacterial mat abundance on Caribbean coral reefs. PLoS One 10: $\mathrm{e} 0125445$.

Brocke, H.J., Wenzhoefer, F., de Beer, D., Mueller, B., van Duyl, F.C. \& Nugues, M.M. (2015b) High dissolved organic carbon release by benthic cyanobacterial mats in a Caribbean reef ecosystem. Scientific Reports 5: 8852.

Burke, L., Reytar, K., Spalding, M. \& Perry, A. (2011) Reefs at Risk Revisited. Washington, DC, USA: World Resources Institute.

Cardini, U., Bednarz, V.N., Foster, R.A. \& Wild, C. (2014) Benthic $\mathrm{N}_{2}$ fixation in coral reefs and the potential effects of humaninduced environmental change. Ecology and Evolution 4: 17061727.

Catala, R.L. (1957) Report on the Gilbert Islands: some aspects of human ecology. Atoll Research Bulletin 59: 256.

Cinner, J. (2005) Socioeconomic factors influencing customary marine tenure in the Indo-Pacific. Ecology and Society 10: 36.

Cooper, T.F., Gilmour, J.P. \& Fabricius, K.E. (2009) Bioindicators of changes in water quality on coral reefs: review and recommendations for monitoring programmes. Coral Reefs 28: 589-606.

Fabricius, K.E., Cooper, T.F., Humphrey, C., Uthicke, S., De'ath, G., Davidson, J., LeGrand, H., Thompson, A. \& Schaffelke, B. (2012) A bioindicator system for water quality on inshore coral reefs of the Great Barrier Reef. Marine Pollution Bulletin 65: 320332.

Friedlander, A.M. \& DeMartini, E.E. (2002) Contrasts in density, size, and biomass of reef fishes between the northwestern and the main Hawaiian islands: the effects of fishing down apex predators. Marine Ecology Progress Series 230: 253-264.
Froese, R. \& Pauly, D. (eds) (2013) FishBase [www document]. URL http://www.fishbase.org.

Green, A.L. \& Bellwood, D.R. (2009) Monitoring Functional Groups of Herbivorous Fishes as Indicators for Coral Reef Resilience - A Practical Guide for Coral Reef Managers in the Asia Pacific Region. IUCN Working Group on Climate Change and Coral Reefs. Gland, Switzerland: IUCN.

Hamilton, R.J., Giningele, M., Aswani, S. \& Ecochard, J.L. (2012) Fishing in the dark - Local knowledge, night spearfishing and spawning aggregations in the Western Solomon Islands. Biological Conservation 145: 246-257.

Hughes, T.P., Rodrigues, M.J., Bellwood, D.R., Ceccarelli, D., Hoegh-Guldberg, O., McCook, L., Moltschaniwskyj, N., Pratchett, M.S., Steneck, R.S. \& Willis, B. (2007) Phase shifts, herbivory, and the resilience of coral reefs to climate change. Current Biology 17: 360-365.

Kline, D.I., Kuntz, N.M., Breitbart, M., Knowlton, N. \& Rohwer, F. (2006) Role of elevated organic carbon levels and microbial activity in coral mortality. Marine Ecology Progress Series 314: 119-125.

Kuffner, I.B. \& Paul, V.J. (2004) Effects of the benthic cyanobacterium Lyngbya majuscula on larval recruitment of the reef corals Acropora surculosa and Pocillopora damicornis. Coral Reefs 23: 455-458.

Labrosse, P., Kulbicki, M. \& Ferraris, J. (2002) Undermater Visual Census Surveys - Proper Use and Implementation. Noumea, New Caledonia: Secretariat of the Pacific Community (SPC).

MacNeil, M.A., Graham, N.A.J., Cinner, J.E., Wilson, S.K., Williams, I.D., Maina, J., Newman, S., Friedlander, A.M., Jupiter, S., Polunin, N.V.C. \& McClanahan, T.R. (2015) Recovery potential of the world's coral reef fishes. Nature 520: 341-344.

Nagle, D.G. \& Paul, V.J. (1998) Chemical defense of a marine cyanobacterial bloom. Fournal of Experimental Marine Biology and Ecology 225: 29-38.

National Statistics Office (2014) National Population and Housing Census 2011. Port Moresby, Papua New Guinea: National Statistics Office, Papua New Guinea.

O'Leary, T., Leeming, R., Nichols, P.D. \& Volkman, J.K. (1999) Assessment of the sources, transport and fate of sewagederived organic matter in Port Phillip Bay, Australia, using the signature lipid coprostanol. Marine and Freshmater Research 50: 547-556.

Pinca, A., Kronen, M., Friedman, K., Magron, F., Chapman, L., Tardy, E., Pakoa, K., Awira, R., Boblin, P. \& Lasi, F. (2010) Regional Assessment Report: Profiles and Results from Survey Work at 63 Sites Across 17 Pacific Island Countries and Territories. Noumea, New Caledonia: Secretariat of the Pacific Community (SPC).

Piniak, G.A., Fogarty, N.D., Addison, C.M. \& Kenworthy, W.J. (2005) Fluorescence census techniques for coral recruits. Coral Reefs 24: 496-500.

Pratchett, M.S., Hoey, A.S. \& Wilson, S.K. (2014) Reef degradation and the loss of critical ecosystem goods and services provided by coral reef fishes. Current Opinion in Environmental Sustainability 7: 37-43.

R Development Core Team (2013) R: a language and environment for statistical computing. $\mathrm{R}$ Foundation for Statistical Computing, Vienna, Austria [www document]. URL http://www.R-project.org/

Risk, M.J., Heikoop, J.M., Edinger, E.N. \& Erdmann, M.V. (2001) The assessment "toolbox": community-based reef evaluation methods coupled with geochemical techniques to identify sources of stress. Bulletin of Marine Science 69: 443-458. 
Risk, M.J., Lapointe, B.E., Sherwood, O.A. \& Bedford, B.J. (2009) The use of $\delta 15 \mathrm{~N}$ in assessing sewage stress on coral reefs. Marine Pollution Bulletin 58: 793-802.

Roff, G. \& Mumby, P.J. (2012) Global disparity in the resilience of coral reefs. Trends in Ecology and Evolution 27: 404-413.

Venables, W.N. \& Ripley, B.D. (2002) Modern Applied Statistics with $S$. Fourth edition. New York, NY, USA: Springer.

Wear, S.L. \& Thurber, R.V. (2015) Sewage pollution: mitigation is key for coral reef stewardship. Annals of the Nem York Academy of Sciences 1355: 15-30.

Wickham, H. (2009) ggplot2: Elegant Graphics for Data Analysis. New York, NY, USA: Springer Science and Business Media.
Wild, C., Rasheed, M., Jantzen, C., Cook, P., Struck, U., Huettel, M. \& Boetius, A. (2005) Benthic metabolism and degradation of natural particulate organic matter in carbonate and silicate reef sands of the northern Red Sea. Marine Ecology Progress Series 298: 69-78.

Wild, C., Jantzen, C., Struck, U., Hoegh-Guldberg, O. \& Huettel, M. (2008) Biogeochemical responses following coral mass spawning on the Great Barrier Reef: pelagic-benthic coupling. Coral Reefs 27: 123132.

Zann, L.P. (1994) The status of coral reefs in South Western Pacific Islands. Marine Pollution Bulletin 29: 52-61. 